\title{
GSM Based ATM Security ATM Banking
}

\author{
Miss Sanchita R Jantre ${ }^{1}$, Mr. Ratnakar A. Kharade ${ }^{2}$ \\ Dept. of E\&TC, Dr. Daulatrao Aher College of Engineering, Karad, India ${ }^{1}$ \\ Assistant Professor, Dept. of E\&TC, Dr. Daulatrao Aher College of Engineering, Karad, India ${ }^{2}$
}

\begin{abstract}
Now a day the idea of designing the Security Based ATM banking system project is born with the observation in our real-life incidents happening around us. This GSM base project deals with avoidance of ATM theft from robbery. So, overcome the deficiency found in existing technology in our society. We are implement the new proposed system. In this system, we provide GSM based security. In case when we lost the ATM card or theft form robbery then we are essay block the transaction in proposed system. we provide double security to ATM money transaction. First, when ATM user Insert the ATM in ATM machine, he can type the password and second, then message goes through card holder via GSM then card holder can send the security code or OTP using GSM through main system and start the transaction via card holder. When we lost the ATM card then in second case card holder cannot send the security code and stop the transaction and he directly block the card using GSM system.
\end{abstract}

Keywords: GSM, AT89C51 Microcontroller, LCD, Flash magic, Keil tool.

\section{INTRODUCTION}

In today's technically advanced and developed world, autonomous systems are improvement rapid popularity in world. As the social computerization, automation and developed technics has been increased and the ATM and credit card has been installed and spread out to simplify the financial activity, the banking activity has been simplified so more, however the crime related with financial organization has been increased over numbers in the world in proportion to the ratio of spread out of automation, devices and technologies.

Now, a day theft from robbery increases gradually. ATM related crime cases are increases. For stop this situation weare put GSM technology in ATM system. We are only change the software by using GSM technology. By using GSM, we provide double security in the ATM banking. So, same amount of robbery can be control.

\section{LITERATURE REVIEW}

The existing self-banking system service has got very high popularity with 24 hours' service to customer. Use of ATM (Automatic Teller Machine) is helpful for money transaction purpose. ATM is activated by placing the card, then putting or entering the pin number of the particular card. But this system is not safe as possible as to use, because anybody can access the system if they have the card and pin number like we share our card and pin number to our friends, family members who may miss use it [1]. There is various existing system are developed such as Security in e-banking via without using ATMs card [2] provides high security in authentication which also protects user from unauthorized access. In this system of model user required personal identity number (pin). Protected cash withdrawal in ATM using mobile phone [3] describes a method of implementing two way authentications.

\section{BLOCK DIAGRAM}

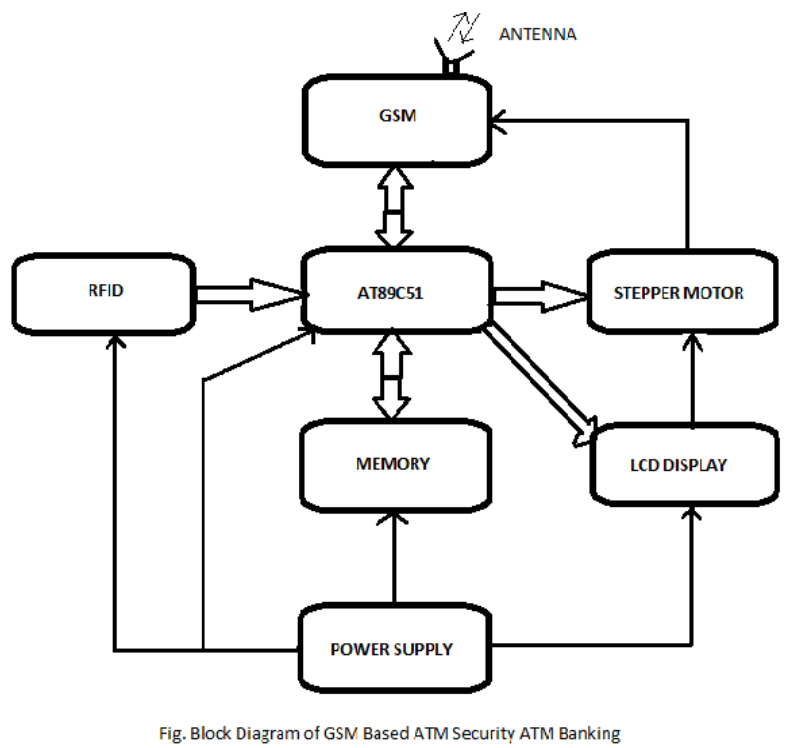

Fig.1. Block Diagram

Hardware required are: -

1. GSM module

2. Power supply

3. AT89C51 Microcontroller

4. LCD

5. RFID

6. Stepper motor

7. Voltage regulator IC 7805

When user can be use ATM in ATM machine, user type the password. Then message send to card holder by interfacing GSM module with AT89C51. This total system can be control by using microcontroller. This all message display on LCD. When transaction start then stepper motor run which is interface with microcontroller. 


\section{PROPOSED SYSYEM}

In existing system drawback overcome in proposed system by using GSM technology. In our project, we provide double security using GSM. When card user insert ATM in ATM machine type the password. Then message goes through card holder using GSM technology. Then card holder provides security code to ATM via message using GSM. Then transaction will be start observe when stepper motor rotates.

\section{HARDWARE DETAILS}

1.GSM module:GSM also call as global system of communication. It is a digital mobile telephony system. GSM initialize and compresses data. GSM module operates at either $900 \mathrm{MHz}$ or $1800 \mathrm{MHz}$ frequency.

2.Power supply: Power supply is the major concern for every electronic device. Since the controller and other devices used are low power devices there is a need to step down the voltage and as well as rectify the output to convert the output to a constant dc. Power supply unit is the basic requirement for electronic devices.

3.AT89C51 Microcontroller: AT89C51 is an 8-bit microcontroller. Its belongs to Atmel's 8051 family. ATMEL 89C51 has 4KB of Flash programmable and erasable read only memory (PROM). Also, it contains 128 bytes of RAM. It can be erased and program to a maximum of 1000 times. This microcontroller interface with whole system.

4. LCD: It is also known as Liquid Crystal Display. (Liquid Crystal Display) screen is an electronic display module. It's have find a wide range of applications. A $16 \times 2$ LCD display is very basic module. It is very commonly used in various devices and circuits. These modules are preferred over seven segment and other multi segment LCDs.

5. RFID: RFID or Radio Frequency Identification is a method in which electromagnetic waves are used for transmitting data for the purpose of identifying tags attached to objects.

6. Stepper motor: A stepper motor is an electromechanical device which converts electrical pulses into discrete mechanical movements. The shaft or spindle of a stepper motor rotates in discrete step increments when electrical command pulses are applied to it in the proper sequence.

7. Voltage regulator IC 7805:A three terminal voltage regulators is a regulator in which the output voltage is set at some predetermined value. Such regulators do not require an external feedback connection. Hence, only three terminals are required for device of such types, input (Vin) output (Vo) and a ground.

\section{SOFTWARE DETAILS}

1.Flash magic: The Keil C51 C Compiler for the 8051 microcontroller is the most popular $8051 \mathrm{C}$ compilers in the world. It provides more features than any other $8051 \mathrm{C}$ compilers available today. The C51 Compiler allows you to write 8051 microcontroller applications in $\mathrm{C}$ that, once compiled, have the efficiency and speed of assembly language. Language extensions in the C51 Compiler give you full access to all resources of the 8051 .

2. Flash magic: NXP Semiconductors produce a range of Microcontrollers that feature both on-chip Flash memory and the ability to be reprogrammed using In-System Programming technology. Flash Magic is Windows software from the Embedded Systems Academy that allows easy access to all the ISP features provided by the devices.

\section{FLOW OF THE SYSTEM}

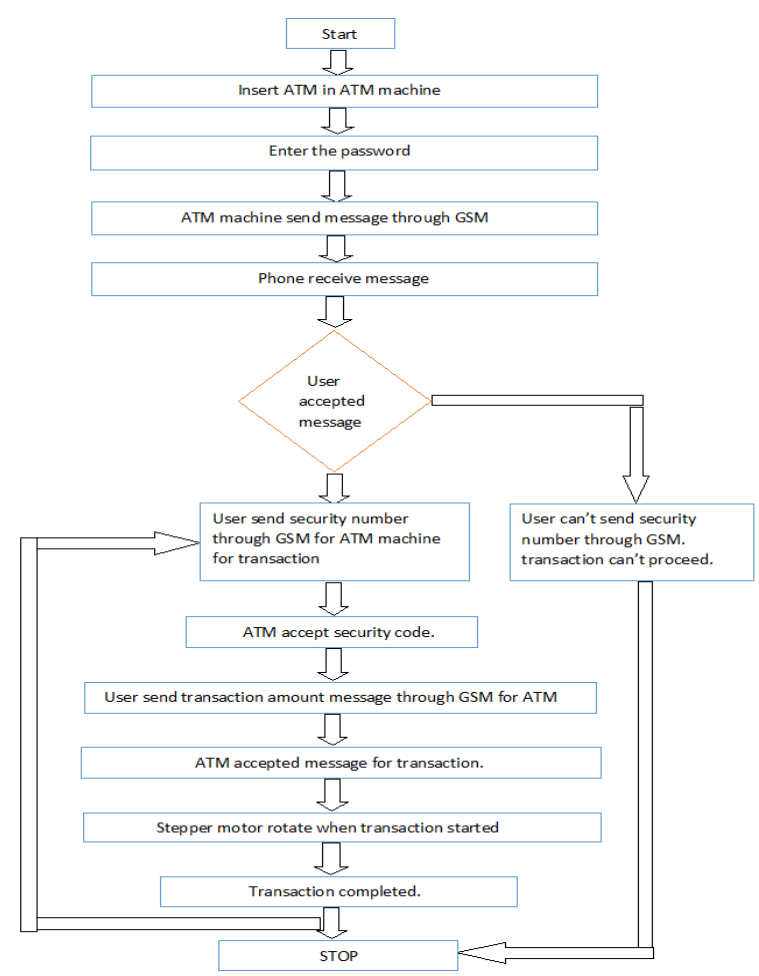

Fig2. Flow chart

\section{ADVANTAGES}

More secure for transaction Instantaneous action by using GSM technology Essay to use GSM related transaction technic Direct mobile communication system involves

\section{CONCLUSION}

This whole implementation ensures us a secured and authenticated transaction through GSM technique with lowest cost and minimum maintenance. Mankind will 
utilize new and secured type of money transactions. The only thing is that initial cost of GSM module of the entire system is the required one-time investment. Account holder will utilize ATM card by entering password through his predefined mobile number for bank. The value-added service that this system provides increases the credibility of the financial institutions, the banks improves the convenience to its customer. Hence as the world progresses through the inevitable and an indomitable quest for knowledge, the aspect of security bound systems is bound to concede with the growing innovations and obviously more vulnerabilities. Hence our application might well solve the aspect of transaction security to a precise and great extent.

\section{REFERENCES}

[1]"Enhanced Atm Security Using Diffrentiated Passwords With Gsm Technology", issue 4, volume 5, May 2015.

[2] "GSM Based Anti-Theft Transaction System",Vol. 4, Issue 1, January 2015 .

[3]"RFID and GSM Based ATM Money TransferPrototype System",Vol.3, Issue 11, November 2014.

[4] "Design and Implementation of Security Based ATM theft Monitoring system", Volume 3, Issue 1, August 2013.

[5] International Journal of Engineering Research \& Technology (IJERT) Vol. 2 Issue 3, March - 2013 ISSN: 2278-0181 ATM Systems Authentication Based on Fingerprint Using ARM Cortex-M3 by Mr. John Mashurano1, M.E Signal and Information Processing. And Mr. Wang liqiang2, Associate Professor, Optics Lab.

[6] M. Dineshkumar, M.S. Geethanjali, R.Karthika, M.Nagaraj, N.Vijayanandam,"Protected Cash Withdrawal in ATM Using Mobile Phone", International Journal Of Engineering And Computer Science, Vol.2, pp.1346-1350, 2013.

[7]R. Rasu, P. Krishna Kumar, M. Chandraman, 'Security for ATM Terminal Using Various Recognition Systems' International Journal of Engineering and Innovative Technology, 4th October 2012.

[8]Binachi.A, Oakley.I and Kwon.D.S, "using mobile device screens for authentication", in proceedings of the 23rd Australian computerhuman interaction conference, ozchi'11, pp. 50-53,2011.

[9] A.D.Luca, M.Langerich and H.Hussma "towards understanding ATMsecurity: a field real world ATM use", in proceedings of the six symposium on usable privacy and security: Redmond, Washington, pp. 1-10, 2010.

[10]Aggarwal, C. C., Wolf, J. L., and Yu, P. S., "Caching on the World Wide Web", IEEE Transactions on Knowledge and Data Engineering, Vol.11, pp.94-107, 2009.

[11] Kumar, K.Shailaja, G.Shailaja, A.Kavitha, A.Saxena, "mutual authentication and agreement for GSM", international conference mobile business (icmb'06), pp. 25-26, 2006.

[12] T.S.Messengers, E.A.Dabbish and R.H.Sloan, "examining smartcard security under the threat of power analysis attacks", IEEE trans.computers, vol.51, no.5, pp.541-552, may 2002. 